\title{
Analysis of Yersinia ruckeri strains isolated from trout farms in northwest Germany
}

\author{
Yidan Huang ${ }^{1}$, Arne Jung ${ }^{2}$, Werner-Johannes Schäfer ${ }^{3}$, Dieter Mock ${ }^{3}$, \\ Geovana Brenner Michael ${ }^{4}$, Martin Runge ${ }^{5}$, Stefan Schwarz ${ }^{4}$, Dieter Steinhagen ${ }^{1, *}$ \\ ${ }^{1}$ Fish Disease Research Unit, University of Veterinary Medicine Hannover, Bünteweg 17, 30559 Hannover, Germany \\ ${ }^{2}$ Clinic for Poultry, University of Veterinary Medicine Hannover, Bünteweg 17, 30559 Hannover, Germany \\ ${ }^{3}$ Landesamt für Natur, Umwelt und Verbraucherschutz Nordrhein-Westfalen (LANUV), Fisheries Ecology, \\ Heinsberger Straße 53, 57399 Kirchhundem-Albaum, Germany \\ ${ }^{4}$ Institute of Farm Animal Genetics, Friedrich-Loeffler-Institut (FLI), Höltystr. 10, 31535 Neustadt-Mariensee, Germany \\ ${ }^{5}$ Lower Saxony State Office for Consumer Protection and Food Safety (LAVES), \\ Food and Veterinary Institute Braunschweig/Hannover, Eintrachtweg 17, 30173 Hannover, Germany
}

\begin{abstract}
Enteric redmouth disease (ERM), caused by Yersinia ruckeri, is among the most important infectious diseases in rainbow trout Oncorhynchus mykiss aquaculture in Europe. Our aim was to analyse the persistence of $Y$. ruckeri strains in trout farms in northwest Germany and their dissemination between farms based on a detailed molecular and phenotypical characterisation scheme. The data on identification and characterisation of Y. ruckeri strains and examining the distribution of these strains in the field could serve as a basis for preventive disease monitoring plans. During the observation period from June 2011 until June 2012, we collected 48 Y. ruckeri isolates from 12 different rainbow trout hatcheries. In total, $44(91.7 \%)$ of the isolates were nonmotile; in particular, all isolates recovered during the sampling period in winter and early spring were non-motile. In several trout farms, characteristic farm-specific $Y$. ruckeri isolates from particular typing groups were isolated throughout the year, while in other farms, which had a trading relationship between each other, ERM outbreaks were caused by Y. ruckeri from the same typing group. Our data indicate that in some farms, the causative Y. ruckeri strains persisted in the respective trout farm. The presence of $Y$. ruckeri from the same typing group in farms with a trading relationship indicates a dissemination of the infection between the farms.
\end{abstract}

KEY WORDS: Epidemiology $\cdot$ Enteric redmouth disease $\cdot$ Rainbow trout $\cdot$ Oncorhynchus mykiss

\section{INTRODUCTION}

Enteric redmouth disease (ERM) is a serious disease of farmed rainbow trout Oncorhynchus mykiss that causes economic losses worldwide. The aetiologic agent of ERM, the enterobacterium Yersinia ruckeri, has been isolated from various fish species, including rainbow trout, lake trout Salvelinus namaycush, brown trout Salmo trutta and Atlantic salmon Salmo salar, but mainly affects rainbow trout.
Clinical outbreaks of ERM are characterised by haemorrhages in various tissues, particularly around the mouth, in the muscles, the peritoneum and the lower intestine. Mortality in rainbow trout farms where ERM is present can reach up to $70 \%$ of the total population (Furones et al. 1993). ERM outbreaks can be treated with antibiotics, but it is difficult to eradicate the disease from a farm completely. In the farm environment, Y. ruckeri can survive for several months outside the host in water, sediment or bio- 
films of fish tanks (Furones et al. 1993, Coquet et al. 2002). In addition, infected fish may become asymptomatic carriers and shedders, and may thereby infect other fish. This may happen on the same farm or on other farms when such infected fish have been moved between facilities. Hence $Y$. ruckeri can easily spread from one trout population to another and from one farm to another. In order to prevent devastating disease outbreaks and massive antibiotic treatment, appropriate vaccination and good husbandry is essential (Villumsen et al. 2014). For vaccination, ERM vaccines are mainly applied by the immersion method, which allows vaccinating large numbers of juveniles in a fast and reliable manner (Chettri et al. 2012). Nevertheless, outbreaks of ERM are still periodically observed, in particular in trout farms where $Y$. ruckeri is endemic. These outbreaks have often been linked to the presence of non-motile isolates (assigned as biotype 2, BT 2, isolates). Non-motile BT 2 isolates were found in trout populations in the UK, the European mainland (Austin et al. 2003, Fouz et al. 2006, Ström-Bestor et al. 2010) and North America (Arias et al. 2007). The first isolation from a trout population in Germany dates back to 1994 (Klein et al. 1994). Recently, 'vaccine-tolerant' BT 2 isolates of $Y$. ruckeri were recorded from ERM outbreaks in trout farms in the German federal state of North Rhine-Westphalia (NRW; D. Mock pers. obs). In order to investigate the occurrence and further spreading of these 'vaccine-tolerant' isolates, Y. ruckeri strains isolated from trout farms in NRW were analysed with the molecular and phenotypic characterisation scheme for $Y$. ruckeri developed by Huang et al. (2013).

\section{MATERIALS AND METHODS}

\section{Sample collection}

Rainbow trout were sampled from tanks or ponds of 12 different trout farms in NRW in 2011 to 2012 (Table 1). The farms were located at the headwaters of the Lippe, Lenne, Ruhr and Agger Rivers, which drain into the Rhine, and at the headwaters of the Rur, which drains into the Maas (Fig. 1). All farms were monitored on a regular basis by the veterinarians of the NRW fish health service.

For stocking, all farms purchased eggs from sources certified as disease-free. In 9 of the examined farms, Yersinia ruckeri was endemic, and in 6 farms, the bacterium caused ERM outbreaks on a regular basis. This was confirmed by isolation of Y. ruckeri from tis- sues of clinically diseased fish by the NRW fish health service. An additional 3 farms had no previous ERM disease history. Vaccines raised against motile and non-motile strains of $Y$. ruckeri were applied in 4 farms with ERM outbreaks, while trout in all other farms were not vaccinated (see Table 1). In addition to ERM, infections with Flavobacterium psychrophilum (causing rainbow trout fry syndrome, RFTS) and Aeromonas salmonicida (causing furunculosis) were also present in rainbow trout on some farms (Table 1). For treatment of clinical outbreaks of the bacterial infections, antimicrobial agents (sulphonamides/trimethoprim, amoxicillin or florfenicol) were applied in most farms, while trout in 1 farm were not treated with antimicrobial agents at all (Table 1).

Sampling was conducted during 6 campaigns from June 2011 to June 2012. The water temperature varied from $4^{\circ} \mathrm{C}$ in winter to $18^{\circ} \mathrm{C}$ in summer (Table 2). In the farms, trout with clinical signs indicating a bacterial infection were selected from ponds with clinical outbreaks of ERM, whereas trout from apparently healthy stocks were randomly sampled. An overview of the farm visits during the sampling campaigns, sampled tanks or ponds and the number of collected trout is given in Table S1 in the Supplement, available at www.int-res.com/articles/suppl/ d116p243_supp.pdf.

\section{Isolation of bacteria}

Rainbow trout were transported to the laboratory alive and examined for the presence of a Y. ruckeri infection following the diagnostic procedures of finfish and shellfish pathogens (American Fisheries Society Fish Health Section 2014). Kidney and spleen samples were collected from trout showing clinical signs and inoculated into tryptic soy agar. Y. ruckeri were isolated and identified as described previously (Huang et al. 2013). Briefly, the isolates were examined by Gram staining and were biochemically characterised by API 20E tests (bioMérieux). In addition, repetitive sequence-based PCRs were performed, including BOX-A1R-based repetitive extragenic palindromic-PCR (BOX-PCR), (GTG) 5 -PCR, enterobacterial repetitive intergenic consensus (ERIC) PCR and repetitive extragenic palindromic (REP) PCR, as described by Amann (2007). Moreover, pulsed-field gel electrophoresis (PFGE) of NotI-digested genomic DNA of the $Y$. ruckeri isolates was performed as described previously (Huang et al. 2013). Subsequently, the detailed molecular and phenotypical characterisation scheme based on the API 20E profiles and the 


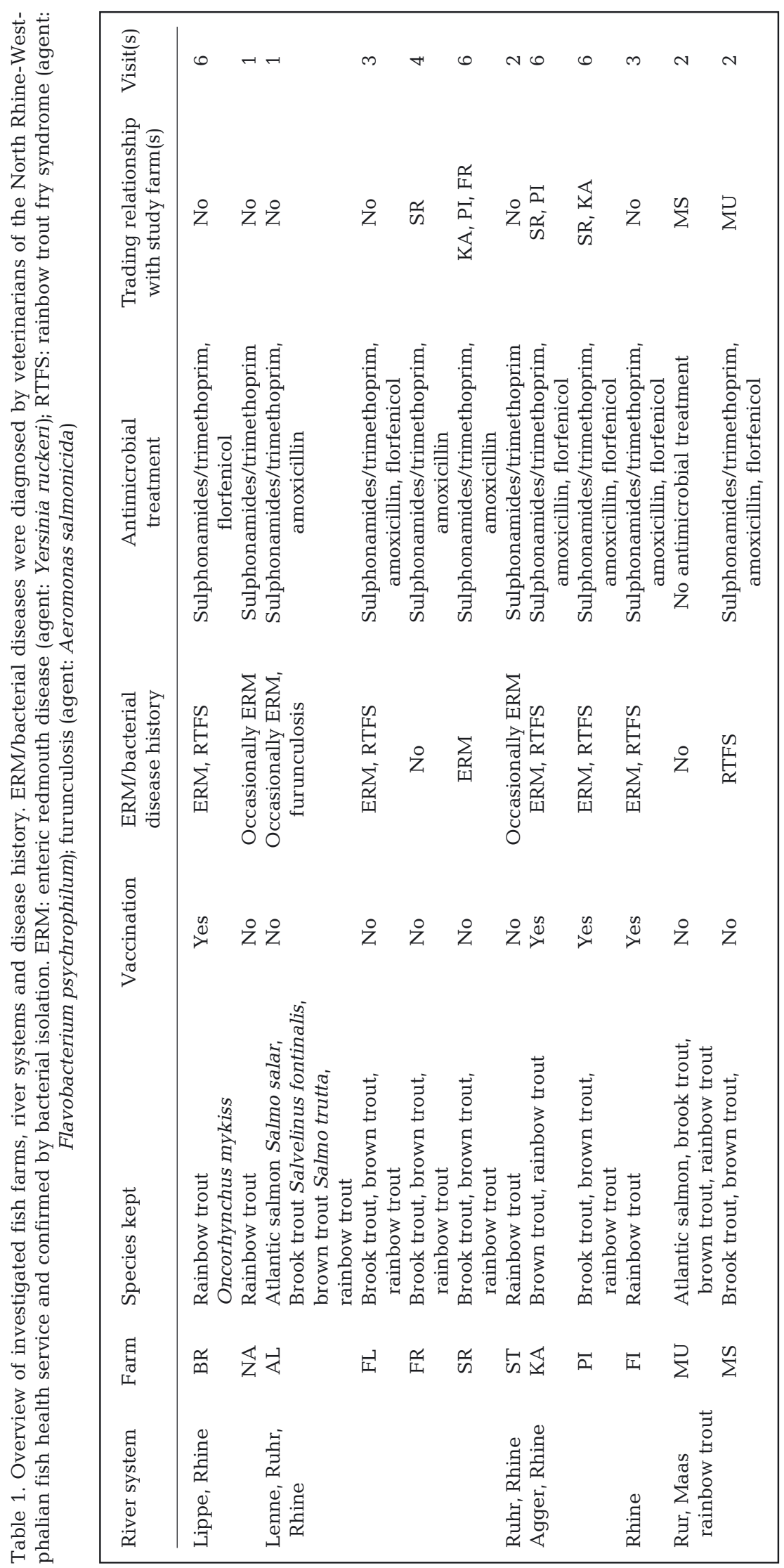

patterns received by PFGE macrorestriction analysis and the above mentioned repetitive sequence-based PCRs (Huang et al. 2013) was applied to investigate the persistence of $Y$. ruckeri isolates in the farms and their dissemination between farms.

\section{RESULTS}

\section{Sample collection in NRW}

During the field study, 12 rainbow trout hatcheries were visited in 6 sampling campaigns in different seasons between 2011 and 2012. In total, 530 rainbow trout from 91 tanks, ponds or raceways were sampled. We were able to isolate Yersinia ruckeri from 183 trout collected from 39 tanks or ponds in 9 trout hatcheries, while Y. ruckeri could not be detected in trout from 3 hatcheries (Tables $2 \&$ S1). During the sampling period, 4 farms with a previous history of ERM outbreaks were visited 6 times. In 2 of these farms (abbreviated SR and PI, see Fig. 1), Y. ruckeri was isolated from $60.5 \%$ and $65.2 \%$ of the sampled trout, respectively (Table 2 ), while in the farms BR and KA, only $42.4 \%$ and $21.7 \%$, respectively, of the examined trout were positive for $Y$. ruckeri.

Y. ruckeri was found in all seasons during the sampling period, but outbreaks of ERM were more frequently diagnosed in summer and early autumn when the water temperature ranged between 10 and $15^{\circ} \mathrm{C}$, compared to samples taken in winter and early spring, when water temperatures were below $10^{\circ} \mathrm{C}$ (Table 3 ). In February 2012, at a water temperature of $4-5^{\circ} \mathrm{C}$, the overall prevalence of $Y$. ruckeri was $25.0 \%$, whereas in September and April, at water temperatures of $10-15$ and $6-8^{\circ} \mathrm{C}$, respectively, $Y$. ruckeri was detected at a prevalence of 31.6 and $31.9 \%$ (Table 3). The sharp decrease in the prevalence of $Y$. ruckeri from to 


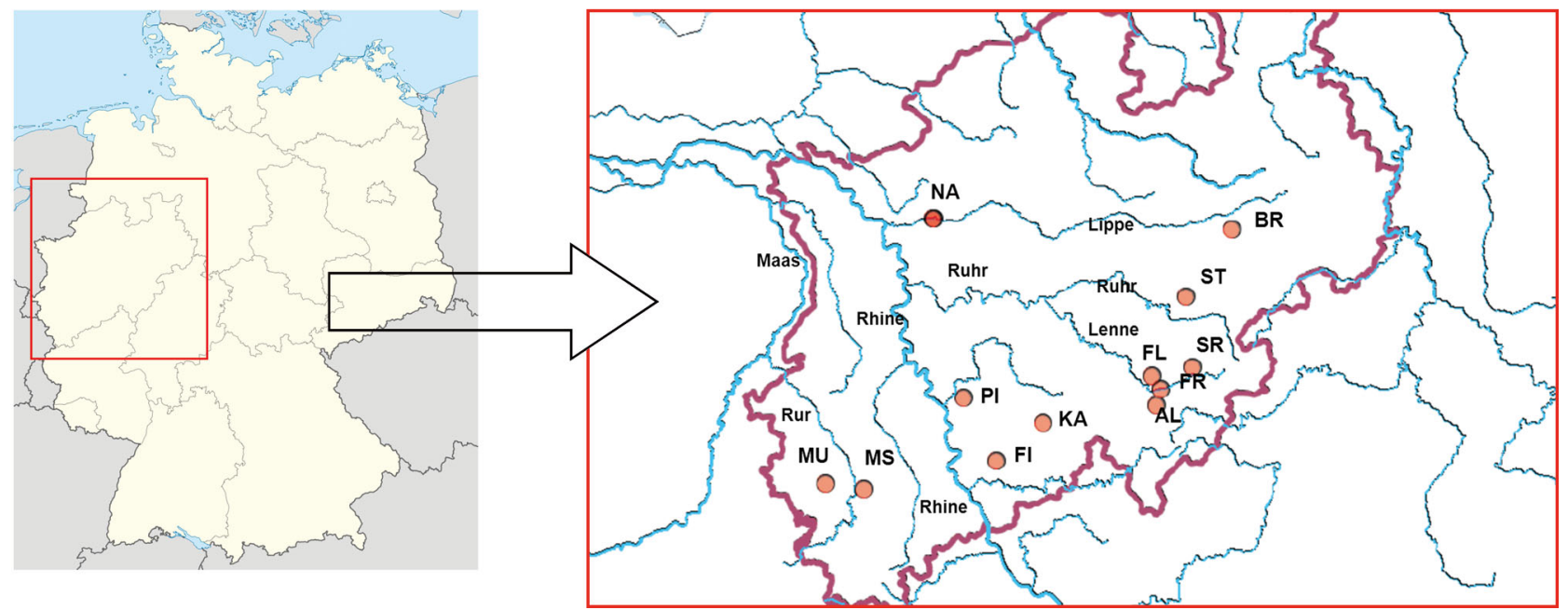

Fig. 1. Geographic origins of Yersinia ruckeri isolates from rainbow trout Oncorhynchus mykiss hatcheries in the federal state of North Rhine-Westphalia, northwest Germany. Farm locations are indicated by 2-letter abbreviations

$61.9 \%$ in June 2011 to $17.3 \%$ in July 2011 resulted from a treatment of infected stocks with antibiotics after clinical outbreaks of ERM in farms BR, FL and KA. Isolates recovered in February and April were found to be non-motile in further tests.

\section{Distribution of Yersinia ruckeri isolates}

During this field study, a total of $48 Y$. ruckeri isolates were obtained from 16 of the 27 typing groups (TP) described by Huang et al. (2013) (Table 3). The TPs were defined according to results obtained from biochemical (API 20 E) and molecular biological typing methods (repetitive PCR and PFGE macrorestriction analysis). In most fish farms, a specific pattern of genetic groups of $Y$. ruckeri was present, and no genetic group was detected in all 9 of the infected farms. Most isolates were non-motile; only Y. ruckeri isolated from diseased trout in farm FL were motile. These isolates from TP 16 were not detected in other farms included in this study and were not detected in seasons when water temperatures were lower than $10^{\circ} \mathrm{C}$ (Table 3 ).

In all farms with recurrent $Y$. ruckeri infections, farm-specific, characteristic isolates from a particular

Table 2. Rates (\%, with number positive/number sampled in parentheses) of Yersinia ruckeri positive rainbow trout Oncorhynchus mykiss in different farms from North Rhine-Westphalia, Germany, during the sampling period

\begin{tabular}{|c|c|c|c|c|c|c|c|}
\hline \multirow{2}{*}{ Farm } & \multicolumn{6}{|c|}{ Sampling times and water temperatures } & \multirow[t]{2}{*}{ Total } \\
\hline & June 2011 & July 2011 & Sept. 2011 & Febr. 2012 & April 2012 & June 2012 & \\
\hline $\mathrm{BR}$ & $81.8(9 / 11)$ & $62.5(5 / 8)$ & $37.5(3 / 8)$ & $41.7(5 / 12)$ & $33.3(3 / 9)$ & $0(0 / 11)$ & $42.4(25 / 59)$ \\
\hline NA & & & $33.3(2 / 6)$ & & & & $33.3(2 / 6)$ \\
\hline $\mathrm{AL}$ & & & $100(2 / 2)$ & & & & $100(2 / 2)$ \\
\hline FL & $57.1(8 / 14)$ & $22.2(2 / 9)$ & $33.3(2 / 6)$ & & & $0(0 / 3)$ & $37.5(12 / 32)$ \\
\hline FR & $0(0 / 17)$ & $0(0 / 10)$ & & $0(0 / 10)$ & & & $0(0 / 37)$ \\
\hline $\mathrm{SR}$ & $81.0(17 / 21)$ & $x^{a}$ & $33.3(3 / 9)$ & $50.0(7 / 14)$ & $56.3(9 / 16)$ & $62.5(10 / 16)$ & $60.5(46 / 76)$ \\
\hline $\mathrm{ST}$ & & & $0(0 / 3)$ & & $x^{a}$ & & $0(0 / 3)$ \\
\hline KA & $60.9(14 / 23)$ & $12.0(3 / 25)$ & $0(0 / 6)$ & $17.7(3 / 17)$ & & $0(0 / 21)^{\mathrm{a}}$ & $21.7(20 / 92)$ \\
\hline PI & $100(12 / 12)$ & $100(4 / 4)$ & $55.6(5 / 9)$ & $0(0 / 4)$ & $0(0 / 5)$ & $75(9 / 12)$ & $65.2(30 / 46)$ \\
\hline FI & & & & $0(0 / 3)$ & & $60.0(3 / 5)$ & $37.5(3 / 8)$ \\
\hline MU & & $0(0 / 8)$ & & & $0(0 / 8)$ & $0(0 / 5)$ & $0(0 / 21)$ \\
\hline MS & & $0(0 / 17)$ & & & & $0(0 / 32)$ & $0(0 / 49)$ \\
\hline Total & $61.9(60 / 97)$ & $17.3(14 / 81)$ & $34.7(17 / 49)$ & $25.0(15 / 60)$ & $31.6(12 / 38)$ & $21.0(22 / 102)$ & $32.3(139 / 431)$ \\
\hline
\end{tabular}


Table 3. Different genetic groups (TP: typing group) of Yersinia ruckeri present in rainbow trout Oncorhynchus mykiss farms in North Rhine-Westphalia, Germany

\begin{tabular}{|c|c|c|c|c|c|c|c|c|}
\hline \multirow{2}{*}{ River system } & \multirow[t]{2}{*}{ Farm } & \multicolumn{6}{|c|}{ Sampling times and water temperatures } & \multirow{2}{*}{ Total } \\
\hline & & $\begin{array}{c}\text { June } 2011 \\
12-15^{\circ} \mathrm{C}\end{array}$ & $\begin{array}{c}\text { July } 2011 \\
15-18^{\circ} \mathrm{C}\end{array}$ & $\begin{array}{l}\text { Sept. } 2011 \\
10-15^{\circ} \mathrm{C}\end{array}$ & $\begin{array}{c}\text { Febr. } 2012 \\
4-5^{\circ} \mathrm{C}\end{array}$ & $\begin{array}{c}\text { April } 2012 \\
6-8^{\circ} \mathrm{C}\end{array}$ & $\begin{array}{c}\text { June } 2012 \\
8-12^{\circ} \mathrm{C}\end{array}$ & \\
\hline \multirow[t]{2}{*}{ Lippe, Rhine } & $\mathrm{BR}^{\mathrm{a}}$ & TP 17 & TP 4 & TP 20 & TP 20 & TP 20 & - & TP $4,17,20$ \\
\hline & NA & & & TP 21 & & & & TP 21 \\
\hline \multirow{4}{*}{$\begin{array}{l}\text { Lenne, Ruhr, } \\
\text { Rhine }\end{array}$} & AL & & & TP 2, 20 & & & & TP 2, 20 \\
\hline & FL & TP 16 & TP 16 & TP 16 & & & - & TP 16 \\
\hline & $\mathrm{FR}^{\mathrm{b}}$ & - & - & & - & & & - \\
\hline & $\mathrm{SR}^{\mathrm{b}}$ & TP 2, 19, 20 & TP 3, 20 & TP 2 & TP 6 & TP 2 & TP 2, 8 & TP $2,3,6,8,19,20$ \\
\hline Ruhr, Rhine & $\mathrm{ST}$ & & & - & & TP 8 & & TP 8 \\
\hline \multirow[t]{2}{*}{ Agger, Rhine } & $\mathrm{KA}^{\mathrm{a}, \mathrm{b}}$ & TP 2 & TP 2 & - & TP 7, 8 & - & TP 26 & ТР $2,7,8,26$ \\
\hline & $\mathrm{PI}^{\mathrm{a}, \mathrm{b}}$ & TP 6,15 & TP 2 & TP 2, 22 & - & - & TP 2 & TP $2,6,15,22$ \\
\hline Rhine & $\mathrm{FI}^{\mathrm{a}}$ & - & & & - & & TP 20 & TP 20 \\
\hline \multirow[t]{3}{*}{ Rur, Maas } & MU & & - & & & - & - & - \\
\hline & MS & & - & & & & - & - \\
\hline & Total & $\begin{array}{c}\text { TP } 2,6,15,16 \\
17,19,20\end{array}$ & $\begin{array}{c}\text { TP } 1,2,3 \\
4,16,20\end{array}$ & $\begin{array}{c}\text { TP } 2,5,16 \\
20,21,22\end{array}$ & TP $6,7,8,20$ & TP $2,8,20$ & TP 2,8,20,26 & \\
\hline
\end{tabular}

TP were regularly found. In addition to isolates from TP 16, which were present during 3 sampling campaigns in farm FL, isolates from TP 2 were recovered regularly from trout in farms SR, KA and PI, and isolates from TP 20 were found regularly in farm BR. In farms BR, SR, KA and PI, additional isolates from further TPs were also present. Most of these isolates were only detected in a particular farm in trout from a single pond during 1 particular sampling campaign. Overall, isolates from 6 different TPs were present in farm SR and isolates from 4 TPs in farms KA and PI. Y. ruckeri from several TPs were recovered from the trout in June, July and September in farms SR and PI, while in farm KA the highest diversity of $Y$. ruckeri isolates was detected in February (Table 3). Hence, a seasonal pattern in the presence of particular TPs or in the presence of a higher diversity of $Y$. ruckeri isolates could not be observed (Table 3).

A specific array of isolates from particular TPs, which could be characteristic for a river system, could not be recognised in farms connected to the same river system including the Lenne, Ruhr or Agger Rivers (Table 3). In contrast to this, Y. ruckeri from specific TPs were present in farms KA, PI and SR, which had a trading relationship between each other. In all 3 infected farms, isolates from TP 2 were frequently detected, and isolates from TP 8 were present as well. Isolates from TP 20 were detected during every sampling campaign and in several farms (BR, AL, SR, PI) which had no obvious links (Table 3).

\section{DISCUSSION}

Since Yersinia ruckeri-induced ERM was reported for the first time in the USA (Rucker 1966), it has become an important infectious disease in trout hatcheries worldwide (Horne \& Barnes 1999). The disease was initially controlled by vaccines prepared with classical motile $Y$. ruckeri strains (Johnson \& Amend 1983), but after appearance and spreading of non-motile variants, the vaccine failed to control infections in Europe (Austin et al. 2003, Wheeler et al. 2009) and the USA (Arias et al. 2007). With the inclusion of both types of strains into the vaccine preparation, an enhancement of protection was achieved (Tinsley et al. 2011), but despite the use of those bivalent vaccines, ERM outbreaks occurred in vaccinated Atlantic salmon in Chile (Bastardo et al. 2011, Navas et al. 2014) as well as in European rainbow trout stocks. In 4 trout farms from the present study, the stocks were vaccinated with a bivalent vaccine, and in 3 of these farms, ERM outbreaks caused by non-motile strains were observed during several sampling campaigns. Infected juveniles or fry introduced into the farm for stocking might have served as a source of these infections (Tobback et al. 2007). The infections might also have originated from in-farm sources because the bacterium was observed to be able to survive in pond sediments or biofilms of tanks in trout farms (Coquet et al. 2002), which then could serve as a source for further disease outbreaks. In the current study, a molecular and phenotypic characterisation scheme for $Y$. ruckeri was applied 
(Huang et al. 2013) to help trace the dissemination route of the $Y$. ruckeri isolates during recurrent disease outbreaks. This characterisation scheme revealed that in the majority of the farms, which were repeatedly sampled, bacteria from different TPS were found, and on several occasions, bacteria of different TPs were simultaneously present in the same farm. In most farms, however, ERM outbreaks were associated with the presence of $Y$. ruckeri from a distinct genetic group, which was characteristic for the specific farm. This could indicate that in those farms, ERM outbreaks most likely originated from sources such as latently infected fish stocks (Rodgers 1992) or contaminated environmental samples (Romalde et al. 1994, Coquet et al. 2002), which persisted in the farm rather than having been introduced from outside. The transmission of $Y$. ruckeri could also be related to wild fish, aquatic invertebrates (McDaniel 1971, Fuhrmann \& Boehm 1983, Willumsen 1989) or birds (Bangert et al. 1988) as putative vectors. In the present study, we could not detect any indication for a contribution of these vectors to a dissemination of $Y$. ruckeri between the examined farms, as no Y. ruckeri strains from a common TP were detected in farms located in the same river system. In addition, farm FR, which had no previous history of $Y$. ruckeri infections and which was located on the same river together with ERM-positive farms, did not experience an ERM outbreak throughout the observation period.

In previous studies, mainly motile strains of $Y$. ruckeri were initially found associated with clinical infections of ERM in rainbow trout (Meier 1986). In the current study, isolates from most trout farms were non-motile, which might indicate that under the pressure of vaccination with vaccines directed against motile and non-motile $Y$. ruckeri, non-motile strains were distributed over several farms in NRW. In particular, bacteria from TPs 2, 8 and 20 were found most frequently. Bacteria from TPs 2 and 8 were isolated from 5 farms with a trading relationship between each other, which could facilitate the distribution of these particular types of the pathogen. However, bacteria from TP 20 were also found in several farms, which had no obvious trading relation.

Outbreaks of ERM were usually associated with challenging environmental conditions, such as poor water quality, excessive stocking densities and high water temperature (Horne \& Barnes 1999). In this study, outbreaks were mainly observed in summer and early autumn, at a water temperature between 10 and $18^{\circ} \mathrm{C}$. Especially, outbreaks caused by motile bacteria from TP 16 were observed during this period of time, supporting the hypothesis that motile strains are more active during warmer seasons (Huang et al. 2014). From June to July 2011, the rate of Y. ruckeripositive rainbow trout decreased from 61.2 to $17.3 \%$, as a result of the usage of antibiotic treatments. However, these measures could not provide $100 \%$ protection, and that may be why the positive rate increased again to $31.9 \%$ in September 2011. In some ponds, outbreaks of ERM were even observed during February and April, when the water temperature was below $10^{\circ} \mathrm{C}$. These outbreaks were associated with non-motile $Y$. ruckeri strains, which were previously found to be more active at lower temperatures.

\section{CONCLUSIONS}

Mainly non-motile strains of Yersinia ruckeri could be isolated from vaccinated and non-vaccinated rainbow trout in NRW during the 13 mo sampling period. When $Y$. ruckeri isolates from different farms were characterised according to a detailed phenotypic and molecular characterisation scheme, in some farms $Y$. ruckeri from the same TP were recovered during ERM outbreaks, indicating that the infection originated from a source within the farm. In other farms, which had a trading relationship between each other, ERM outbreaks were caused by $Y$. ruckeri from the same TP, indicating a dissemination of the infection between the farms. The application of this characterisation scheme for pathogenic $Y$. ruckeri strains allows identifying sources of infections and routes of dissemination as a useful basis for disease prevention and monitoring plans.

Acknowledgements. We thank R. Becker (FLI, Mariensee) and S. Baumann (LAVES) for valuable technical assistance. This work was supported by the Landesamt für Natur, Umwelt und Verbraucherschutz Nordrhein-Westfalen (LANUV). Y.H. received a grant from the China Scholarship Council.

\section{LITERATURE CITED}

Amann S (2007) Untersuchung zur Klassifizierung, Identifizierung und Differenzierung von Yersinia Arten. MSc thesis, University of Vienna

American Fisheries Society Fish Health Section (2014) Blue book. Suggested procedures for the detection and identification of certain finfish and shellfish pathogens, 2014 edn. Available at: www.afs-fhs.org/bluebook/bluebookindex.php

Arias CR, Olivares-Fuster O, Hayden K (2007) First report of Yersinia ruckeri biotype 2 in the USA. J Aquat Anim Health 19:35-40 
Austin DA, Robertson PAW, Austin B (2003) Recovery of a new biogroup of Yersinia ruckeri from diseased rainbow trout (Oncorhynchus mykiss, Walbaum). Syst Appl Microbiol 26:127-131

Bangert RL, Ward AC, Stauber EH, Cho BR, Widders PR (1988) A survey of the aerobic bacteria in the feces of captive raptors. Avian Dis 32:53-62

Bastardo A, Bohle H, Ravelo C, Toranzo AE, Romalde JL (2011) Serological and molecular heterogeneity among Yersinia ruckeri strains isolated from farmed Atlantic salmon Salmo salar in Chile. Dis Aquat Org 93:207-214

> Chettri JK, Raid MK, Kania PW, Buchmann K (2012) Differential immune response of rainbow trout (Oncorhynchus mykiss) at early developmental stages (larvae and fry) against the bacterial pathogen Yersinia ruckeri. Dev Comp Immunol 36:463-474

> Coquet L, Cosette P, Quillet L, Petit F, Junter GA, Jouenne T (2002) Occurrence and phenotypic characterization of Yersinia ruckeri strains with biofilm-forming capacity in a rainbow trout farm. Appl Environ Microbiol 68: $470-475$

Fouz B, Zarza C, Amaro C (2006) First description of nonmotile Yersinia ruckeri serovar I strains causing disease in rainbow trout, Oncorhynchus mykiss (Walbaum), cultured in Spain. J Fish Dis 29:339-346

Fuhrmann H, Boehm KH (1983) An outbreak of enteric redmouth disease in West Germany. J Fish Dis 6:309-311

> Furones MD, Rodgers CJ, Munn CB (1993) Yersinia ruckeri, the causal agent of enteric redmouth disease (ERM) in fish. Annu Rev Fish Dis 3:105-125

Horne MT, Barnes AC (1999) Enteric redmouth disease (Yersinia ruckeri). In: Woo PTK, Bruno DW (eds) Fish diseases and disorders, Vol 3. CABI Publishing, Wallingford, p 484-511

> Huang Y, Runge M, Michael GB, Schwarz S, Jung A, Steinhagen D (2013) Biochemical and molecular heterogeneity among isolates of Yersinia ruckeri from rainbow trout (Oncorhynchus mykiss, Walbaum) in north-western Germany. BMC Vet Res 9:215

> Huang Y, Adamek M, Walker C, Runge M, Steinhagen D (2014) In vitro cytotoxicity and multiplex PCR detection of virulence factors of Yersinia ruckeri isolated from rainbow trout in north-western Germany. Berl Münch Tierärztl Wochenschr 127:233-242

> Johnson KA, Amend DF (1983) Comparison of efficacy of

Editorial responsibility: David Bruno,

Aberdeen, UK several delivery methods using Yersinia ruckeri bacterin on rainbow trout, Salmo gairdneri Richardson. J Fish Dis 6:331-336

Klein BU, Kleingeld DW, Bohm KH (1994) First isolation of a non-motile/tween 80 negative Yersinia ruckeri strain in Germany. Bull Eur Assoc Fish Pathol 14:165-166

McDaniel DW (1971) Hagerman redmouth: a new look at an old fish problem. Am Fish US Trout News 15:14-28

Meier W (1986) Enteric redmouth disease: outbreak in rainbow trout in Switzerland. Dis Aquat Org 2:81-82

Navas E, Bohle H, Herniquez P, Grothusen H, Bustamante F, Bustos P, Mancilla M (2014) Draft genome sequence of the fish pathogen Yersinia ruckeri strain 37551 serotype O1b, isolated from diseased, vaccinated Atlantic salmon (Salmo salar) in Chile. Genome Announc 2:e00858-14

Rodgers CJ (1992) Development of a selective-differential medium for the isolation of Yersinia ruckeri and its application in epidemiological studies. J Fish Dis 15:243-254

Romalde JL, Magarinos B, Pazos F, Silva A, Toranzo AE (1994) Incidence of Yersinia ruckeri in two farms in Galicia (NW Spain) during a one-year period. J Fish Dis 17: 533-539

Rucker RR (1966) Redmouth disease of rainbow trout (Salmo gairdneri). Bull Off Int Epizoot 65:825-830

> Ström-Bestor M, Mustamäki N, Heinikainen S, HirveläKoski V, Verner-Jeffreys D, Wiklund T (2010) Introduction of Yersinia ruckeri biotype 2 into Finnish fish farms. Aquaculture 308:1-5

Tinsley JW, Lyndon AR, Austion B (2011) Antigenic and cross-protection studies of biotype 1 and biotype 2 isolates of Yersinia ruckeri in rainbow trout, Oncorhynchus mykiss (Walbaum). J Appl Microbiol 111:8-16

> Tobback E, Decostere A, Hermans K, Haesebrouck F, Chiers $\mathrm{K}$ (2007) Yersinia ruckeri infections in salmonid fish. J Fish Dis 30:257-268

Villumsen KR, Neumann L, Ohtani M, Kragelund Strøm H, Raida MK (2014) Oral and anal vaccination confers full protection against enteric redmouth disease (ERM) in rainbow trout. PLoS ONE 9:e93845

Wheeler RW, Davies RL, Dalsgaard I, Garcia J and others (2009) Yersinia ruckeri biotype 2 isolates from mainland Europe and the UK likely represent different clonal groups. Dis Aquat Org 84:25-33

Willumsen B (1989) Birds and wild fish as potential vectors of Yersinia ruckeri. J Fish Dis 12:275-277

Submitted: May 6, 2015; Accepted: August 25, 2015

Proofs received from author(s): October 13, 2015 